\title{
PROLAPSED SINGLE SYSTEM URETEROCELE IN A FEMALE ADULT: CASE REPORT
}

\author{
C.G. WAIHENYA
}

\begin{abstract}
SUMMARY
A 36 year old female teacher, presented with a bleeding mass in the introitus, difficult micturition, and dysuria of four months duration. She was a para $3+0$, all spontaneous vertex deliveries, her last delivery was in 2001. She was first seen at a private mission hospital in March 2006 where an attempt to excise the mass was made but was abandoned due to bleeding. She was later discharged and re-admitted to a second mission hospital. On examination the mass was firm, round in shape about $2.5 \mathrm{~cm}$ in diameter, dark red in colour with a catgut stitch and areas of necrosis. The patient was investigated and a diagnosis of a prolapsing ureterocele was made and a transvesical excision was undertaken. A repeat IVP done six months later revealed no hydronephrosis and urea and electrolyte (U/E) were normal. This case is reported to highlight one of the differential diagnoses that should be considered when evaluating masses at the introitus in a female patient. The presentation, diagnosis, and management protocols are discussed. Thus far no local case reports have been established.
\end{abstract}

\section{INTRODUCTION}

A ureterocele is a sacculation of the terminal portion of the ureter. It may be either intravesical or ectopic, in the latter case, some portion is located at the bladder neck or in the urethra. Intravesical ureteroceles are associated most often with single ureters whereas ectopic ureteroceles nearly always in the upper pole of duplicated ureters.

Ectopic ureteroceles are more common than intravesical ureteroceles (1). Ureteroceles occur seven times more often in girls than in boys and about $10 \%$ of cases are bilateral. They occur almost exclusively in Caucasians. Eighty per cent of all ureteroceles arise from upper poles of duplicated systems. Mild types of ureteroceles are found occasionally in adults examined for unrelated reasons.

A ureterocele that extends through the bladder neck and the urethra and presents as a vaginal mass in girls is termed as prolapsing ureterocele (2). This mass can be distinguished from other interlabial masses (e.g. rhabdomyosarcoma, urethral prolapse, hydrometocolpos, peri-urethral cysts) by virtue of its appearance and location $(3,4)$.

\section{CASE REPORT}

A 36 year old female teacher by profession presented with a bleeding mass in the introitus, difficult micturition, and dysuria for four months. She was a para $3+0$, all spontaneous vertex deliveries; last delivery was in the year 2001 and was uneventful. There was no history of any instrumentation after last delivery and she was a symptomatic until her presentation.

The patient was first seen at a private mission hospital in March 2006 where attempts at excising the mass were made and abandoned due to bleeding. She was later discharged but re-admitted to a second mission hospital. An ultrasound revealed a left sided ureterocele. Aleft sided hydroureteronephrosis with a poorly secreting kidney and right hydronephrosis.

The prolapsing ureterocele was reduced and a folley's catheter inserted. Since the diagnosis was 
folley's catheter inserted. Since the diagnosis was not in doubt cystoscopy was not done. Furthermore this would have increased the cost of management which the patient could not afford, however the role of cystoscopy in diagnosis of ureterocele is not in doubt.

On 8th April 2006 the patient was taken to theatre and a laparotomy done through a lower midline incision. The bladder was opened though a midline longitudinal incision. An intramural left ureterocele about $2-3 \mathrm{~cm}$ was found and excised. The ureter was spatulated and stitched to the bladder mucosa with Vicryl $3 / 0$ on a round bodied needle. A JJ stent

\section{Figure 1}

The prolapsing ureterocele when the patient presented to us. Note the catgut stitch that was used to stop the bleeding after an attempt at excision

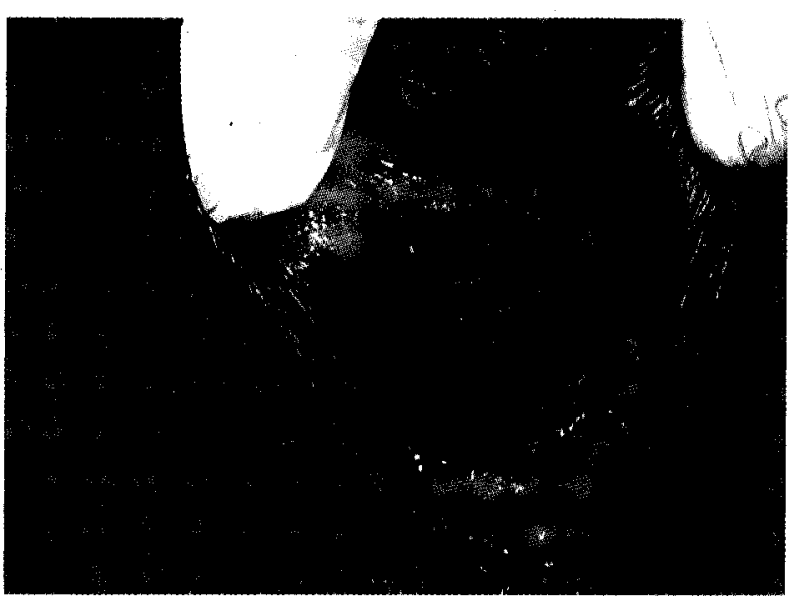

Figure 3

An ultrasound reveals the ureterocele

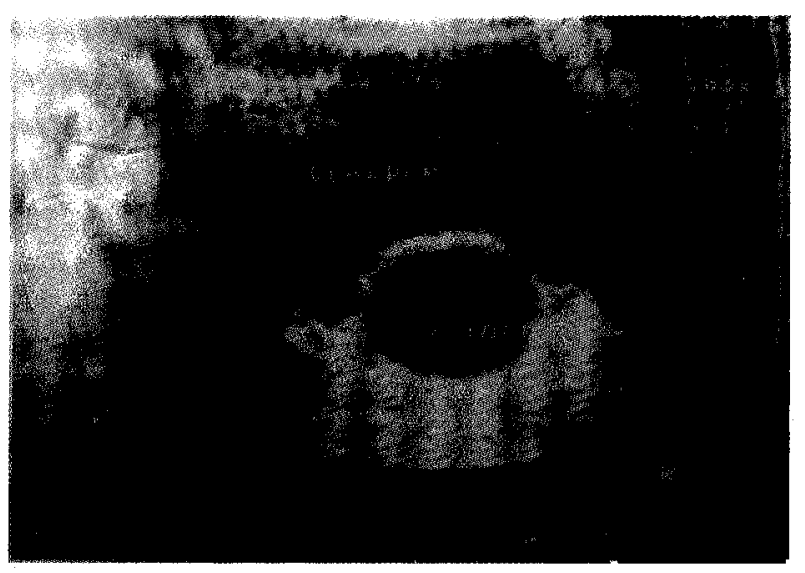

was inserted and a transurethral and a suprapubic catheter inserted. The bladder was closed in a continuous single layer with Vicryl $2 / 0$, a drain was placed in the retropubic space and the wound closed en mass with nylon 1 . The skin was closed with $3 / 0$ nylon. The patient did well postoperatively. The drain was removed after 48 hours when it stopped draining. On the 10th post operative day the catheters were removed and the patient discharged home. The JJ stent was removed after six weeks cystoscopically. A repeat IVP done six months later revealed no hydronephrosis and the urea and electrolytes were normal. The patient has been subsequently reviewed. and is asymptomatic.

\section{Figure 2}

The prolapsing ureterocele was manually reduced and a catheter inserted

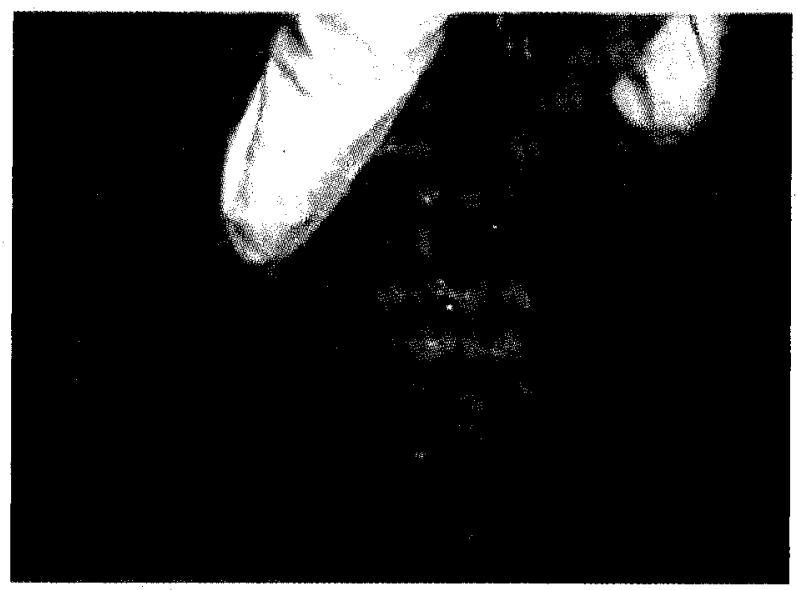

Figure 4

An IVP showing a poorly secreting right kidney and standing column left ureter. The ureterocele can be seen as a filling defect in the bladder

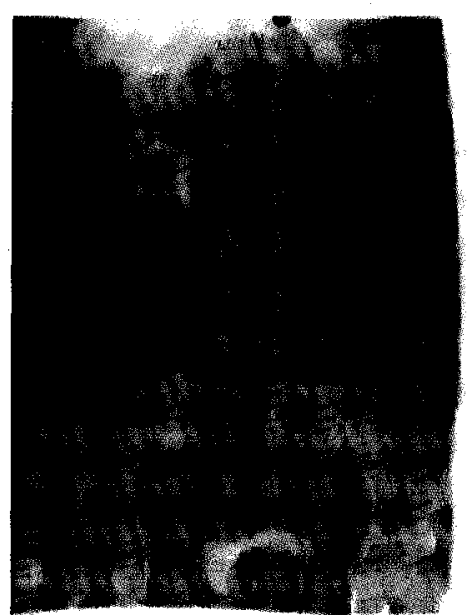


Figure 5

The ureterocele was resected after opening the bladder

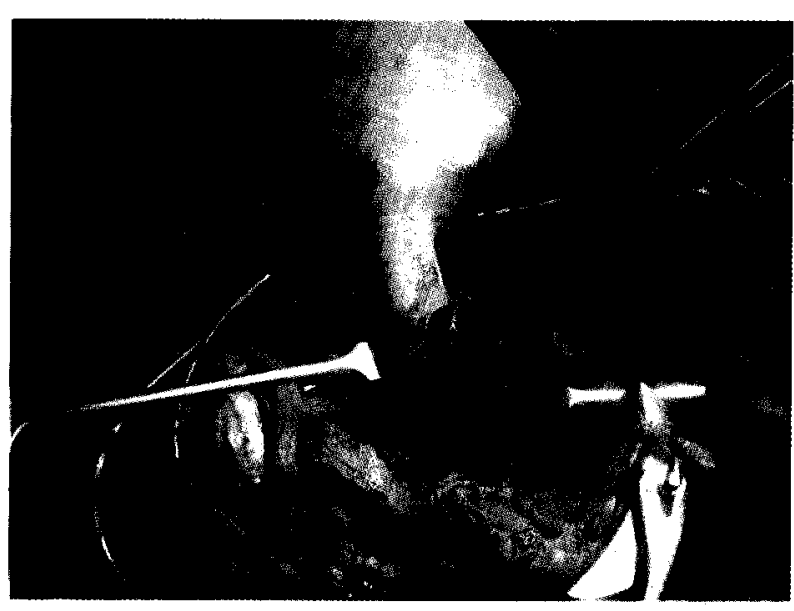

\section{DISCUSSION}

A ureterocele that extends through the bladder neck and the urethra and presents as a vaginal mass in girls is termed as prolapsing ureterocele (2). This mass can be distinguished from other interlabial masses (e.g. rhabdomyosarcoma, urethral prolapse, hydrometocolpos, peri-urethral cysts) by virtue of its appearance and location $(3,4)$. The prolapsing ureterocele has a smooth, round wall in contrast to the grape like cancer that typifies rhabomyosarcoma. The colour may vary from pink to bright red and due to necrotic tissue; shades of blue, purple or brown, may also be encountered. The ureterocele usually slides down the posterior wall of the urethra and therefore it can be demonstrated anterior to the mass and can be catheterised. The vagina (and the corresponding masses that emanate from it; such as hydrometocolpos) is posterior to the ureterocele.

Ureteroceles are congenital abnormalities that present in children but may present in adults. It is not clear why they sometimes present in adults. In this case there were no obvious precipitating factors with regards to the onset of symptoms, and her deliveries were neither prolonged or difficult.

Clinical findings vary considerably. Patients commonly present with infection, but bladder outlet obstruction or incontinence may be the initial complaint. Calculi can develop secondary to urinary stasis and are often seen in the distal ureter. The prolapse can be intermittent and may cause vesicle obstruction, consequently, bilateral renal obstruction as in this ease.

Alternatively the patient may be able to void around the utererocele. In the former scenario, the patient may have varying degrees of hydronephrosis and azotemia and may be septic.

Excretory urogram is usually diagnostic and may show a cystic dilatation or a filling defect in the bladder as in this case. The urethrogram also indicates the degree of hydronephrosis and may reveal a duplicated kidney (5). In this particular case there was no evidence of a duplex.

Sonography has replaced the excretory urography in most centres, as for this case the ureterocele was clearly demonstrated with very little doubt to what we were dealing with. Voiding cystourethrography should always be part of the work up (5). It may demonstrate refill into the lower pole or contra lateral ureter and occasionally shows eversion of the ureterocele during urination in which case the ureterocele has the appearance of a diverticulum, in our patient this was not done due to limitation of funds. Renal scanning is helpful for estimating renal function (6).

Treatment must be individualised. Transurethral incision (endoscopic incision) was used previously only in very ill children with polyhydronephrosis however, it has been recognised as the definitive procedure in many instances particularly in patients with intravesical ureteroceles $(7,8)$. When an open operation is needed, the procedure must be chosen on the basis of the anatomic location of the ureteral meatus, the position of the ureterocele and the degree of hydroureteronephrosis and impairment of the renal function. In general, choices range from heminephrectomy and ureterectomy to the excision of the ureterocele, vesical reconstruction and ureteral reimplantation (9). Often a second procedure is necessary. In this case we chose the open method because the ureterocele was prolapsing, had necrotic areas and that part of the ureter was destroyed by the previous attempt at excision.

\section{REFERENCES}

1. Snyder, H.M. and Johnson, J.H. Orthotopic ureteroceles in children. J. Urol. 1978; 119: 543.

2. Ahmed, S. Prolapsed single system ureterocele in a girl. J. Urol. 1984; 132: 1180. 
3. Witherington, R. and Smith, A.M. Management of prolapsed ureterocele: Past and present. J. Urol. 1979; 121: 813 .

4. Nussbaum, A.R. and Lebowitz, R.I. Interlabial masses in little girls: Review and imaging recommendations. Amer. J. Roentgenol. 1983; 141: 65.

5. Bauer, S.B. and Retik, A.B. The non-obstructive ectopic ureterocele. J. Urol. 1978; 119: 804.

6. Geringer, A.M., Berdon, W.E., Seldin, D.W., et al. The diagnostic approach to ectopic ureterocele and the renal duplication complex. J. Urol. 1983a; 129: 539.
7. Blythe, B., Passerini, G.G., Camuffoc, et al. Endoscopic incision of ureteroceles: Intravesical versus ectopic. J. Urol. 1993; 149: 556.

8. Pfister, C., Ravasse, P., Barret, E., et al. The value of endoscopic treatment for ureteroceles during the neonatal period. J. Urol. 1998; 159: 1006-1009.

9. Husmann, D.A., Ewalt, D.H., Glenski, W.J., et al. Ureterocele associated with ureteral duplication and a non-functioning upper pole segment: management by partial nephroureterectomy alone. J. Urol. 1995; 154: 723-726. 